\title{
Implementation of Farm Weeding and Soil Moisturization Techniques using Agribot
}

\author{
Shalini S, Kalaiselvi S, Logeshwari M, Pavithra P
}

\begin{abstract}
Agriculture plays a vital role in Indian economy sector as it contributes about $17 \%$ to the total GDP. This agribot project aims at reducing the work of farmers in addition to increasing the speed and accuracy of the work. It fulfills the fundamental functions of agriculture such as seed sowing, fertilizer mist and arm gripper. The above feature is carried out using Arduino mega 2560, soil moisturization sensor, temperature sensor (LM35 sensor), L293D driver, DC servo motor, ESP8266 module, relay, power supply, WIFI camera and mobile app. Our project work is implemented using IOT methodology. This system is efficient and operator friendly. This is particularly important for workers in the area where health and jobs are potentially harmful.
\end{abstract}

Keywords: Agribot, Android App, IoT, Sowing, Spraying, Weeding.

\section{INTRODUCTION}

Agriculture is the science and art of breeding plants and animals. More than 70 percent of rural households are dependent on agriculture as their main livelihood. Agribots are being gradually deployed all over the world to help the farmers and improve productivity, resulting in far more precise and smarter operations. The robot begins its work by sensing the soil moisturization content and temperature followed by seed sowing, weeding and spraying. It uses core components such as Arduino mega 2560, L293D driver, Dc servo motor, relay, soil moisturization sensor, temperature sensor (LM 35 sensor), ESP8266 module, WIFI camera, power supply and mobile app.

\section{EXISTING METHOD}

\section{A. IoT Based Precision Agriculture using Agribot}

Many states in India are agrarian economies and rural populations rely on agriculture and animal husbandry for their livelihood. Due rise in labor shortages interest, the production of autonomous vehicles such as robots in agriculture has risen in recent years. The proposed system [1] aims to develop autonomous agricultural robotic vehicles for multipurpose seeding and spraying of pesticides that can be regulated by IoT.

Revised Manuscript Received on February 05, 2020.

* Correspondence Author

Shalini S, ME, Assistant Professor (ECE) in Sri Krishna College of Technology, Coimbatore.

Kalaiselvi S, UG Scholar, Department of Electronics and Communication Engineering, Sri Krishna College of Technology,Coimbatore. Email ID: 16tuec108@skct.edu.in

Logeshwari M, UG Scholar, Department of Electronics and Communication Engineering, Sri Krishna College of Technology, Coimbatore.Email ID: 16tuec118@skct.edu.in

Pavithra P, UG Scholar, Department of Electronics and Communication Engineering, Sri Krishna College of Technology, Coimbatore. Email ID:16tuec147@skct.edu.in

(C) The Authors. Published by Blue Eyes Intelligence Engineering and Sciences Publication (BEIESP). This is an open access article under the CC BY-NC-ND license (http://creativecommons.org/licenses/by-nc-nd/4.0/)
The robot is housed in the farm and is powered on via IoT and its functions are managed by web browser. The backbone of the system is microcontroller (Arduino uno). The microcontroller in the proposed model supports multiple field functions according to the commands received from smart phone.

\section{B. IoT based agri-bot for backyard farming}

In this paper [2], the concept of smart and sustainable farming practices referred to as Agribot was formulated.

From seed sowing to fertilization the whole method is numerically regulated and therefore fully automated. The proposed idea discusses two components, one being the $\mathrm{Wi}$ $\mathrm{Fi}$ and the other being the driver chain. The Wi-Fi board consists of raspberry pi 0 and aurdino atmega 328 .

\section{IoT based Solar Powered Agribot for Irrigation and Farm Monitoring}

In this paper [3], an Agribot is designed that functions as an IoT platform to monitor farmland remotely and also to irrigate the farmland. The Agribot developed is solar powered, consequently harvests solar energy when not irrigated.

\section{Multipurpose Agribot}

In this paper [4], a multipurpose agribot is designed for performing functions like seeding, spraying of pesticides and water. Arduino UNO functions as the heart of the system which collects commands from the transmitter remote control.

\section{PROPOSED METHOD}

The designed "Agribot" will irrigate the field by receiving consumer inputs such as seed sowing, weeding, pesticide sprinkling and watering. The user inputs listed above are given through android app. This reduce the time spent by the farmer in the fields of work and to solve the health problems for the workers.

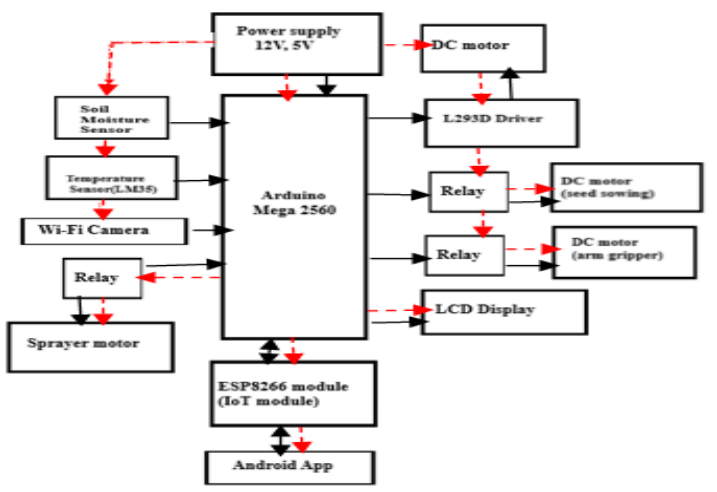

Fig .1.Block Diagram Of Agribot 
The dotted red line in Fig .1. refers the power supply connection and black line in Fig .1. refers the commands given to and from Arduino Mega 2560 . Arduino Mega2560 is interfaced with power supply, soil moisture sensor, temperature sensor, Wi-Fi camera, relay, IOT module, L293D driver and LCD display. By using the user credentials, the user can view the features like detecting the soil moisture and temperature value, Wi-Fi camera, sprayer motor, seed sowing, arm gripper and LCD display in Android App. Microcontroller, soil moisture sensor, temperature sensor, LCD display and IOT module works under $5 \mathrm{v}$ power supply. Servo motor, L293D driver, arm gripper, relay and seed sower works under $12 \mathrm{v}$ power supply. Using IOT technology, communication is established between the user and agribot. After knowing the soil moisture value, if the detected value is less than the value fed in the microcontroller, we can perform spraying function or if the detected value is greater than the value fed in the microcontroller, there is no need to perform spraying operation. By using L293D driver, servo motor moves the wheels in left, right, forward, backward direction. After this, seed sowing function takes place. Seed is sowed at regular intervals. If we press arm gripper feature, weeds can be cleared. LCD display will display the soil moisture and temperature value. Using Wi-Fi camera, the user can monitor the activities happening in the farmland, growth of plants and so on.

Table 1: Ideal Moisture levels for three major types of soils.

\begin{tabular}{|l|l|l|l|}
\hline Soil Type & $\begin{array}{l}\text { No } \\
\text { Irrigation } \\
\text { Needed }\end{array}$ & $\begin{array}{c}\text { Irrigation to } \\
\text { be applied }\end{array}$ & $\begin{array}{c}\text { Dangerously } \\
\text { Low Soil } \\
\text { Moisture }\end{array}$ \\
\hline $\begin{array}{l}\text { Fine } \\
\text { (Clay) }\end{array}$ & $80-100$ & $60-80$ & Below 60 \\
\hline $\begin{array}{l}\text { Medium } \\
\text { (Loamy) }\end{array}$ & $88-100$ & $70-88$ & Below 70 \\
\hline $\begin{array}{l}\text { Coarse } \\
\text { (Sandy) }\end{array}$ & $90-100$ & $80-90$ & Below 80 \\
\hline
\end{tabular}

The above table [5] is a general reference table which is broadly applicable for three major types of soil.

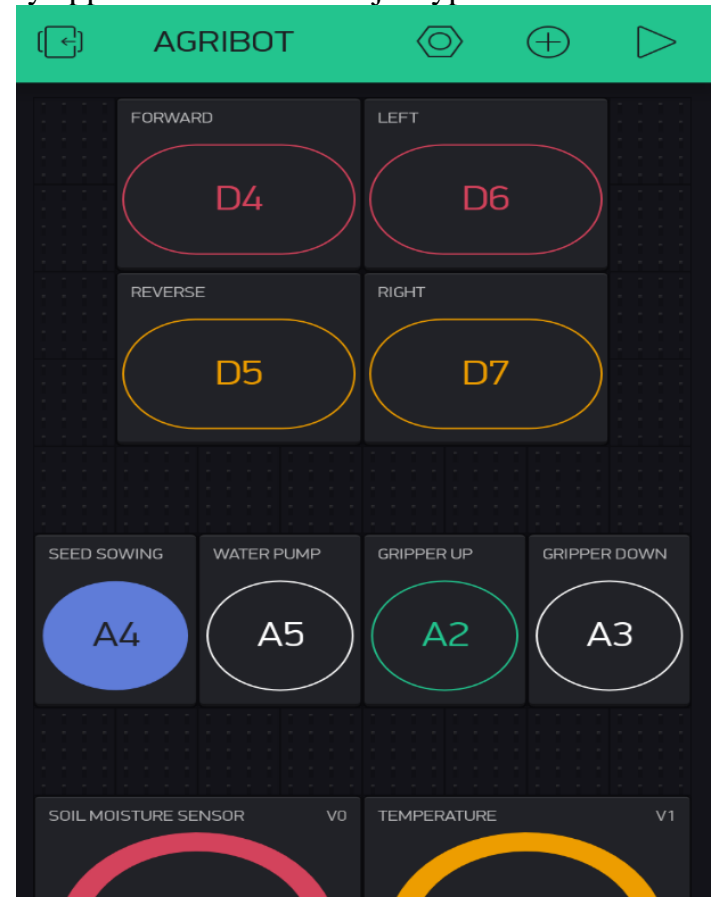

Fig .2.Android app (User Interface)
The above Fig .3. is the Android app developed using blynk server.With the help of this Android app, communication is established between hardware and user.

\section{A. SIMULATION WITH PROTEUS}

1. Start the program by clicking in Start menu on the ISIS 7 Professional icon.

2. Designing the connections: The design of the robot's schematic diagram requires knowledge of the components needed during design.

3. All the components can be selected from the component library and placed here.

4. Wire pencil can be used to provide the contacts between the parts.

5. Tap Library>Select Device/Symbol or simply click "P" to pick the components.

6. So the components used in this design are:

- Arduino Mega 2560

- IOT Module

- L293D driver

- Servo motor

- LCD display

- Relay

The selected component can be seen in the design diagram on the left side window. To place the component on the sheet of design, just left click the component and place it on the sheet, to move the components, right click the component, then left click it and finally drag the component to the desired location.The component is not selected from library for power terminal and ground. At the left side of toolbar, click the "inter-sheet terminal symbol". Each component should be configured to satisfy the specifications. Choose the component(right click) and then left click to open the edit component dialog to edit the component. Based on the devices the dialog is specific.

\section{B. ARDUINO MEGA2560 PARAMETER SETTINGS}

The most important part of proteus simulation is microcontroller configuration. To deal with any configuration fault in time for system execution, the setup must be right. To modify the microcontroller parameter, right click the microcontroller to select the component and then left click. Choose the directory wher the source code was compiled and then pick the corresponding hex file.

\section{SIMULATION}

After the assembly and configuration of the circuit, it is now time to check whether the compiled code is virtually accurate or not. Click the PLAY button at the bottom toolbar to start the simulation.

When the PLAY button is pressed, soil moisture and temperature value get displayed in LCD display and virtual terminal. When we click the STOP button on the simulation, simulation stops. By pressing the button on the Android App for IOT module( i.e., whether the robot to move in left, right, forward, backward direction or functions like seed sowing, spraying, arm gripper),accordingly the motor rotates. 


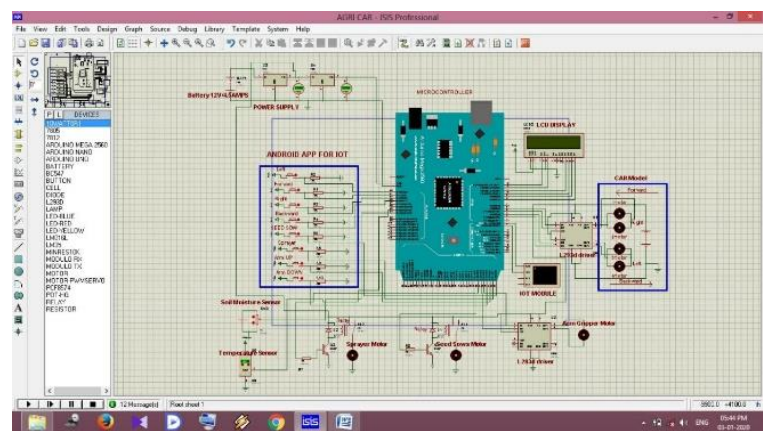

Fig .3. Simulation environment before obtaining output.

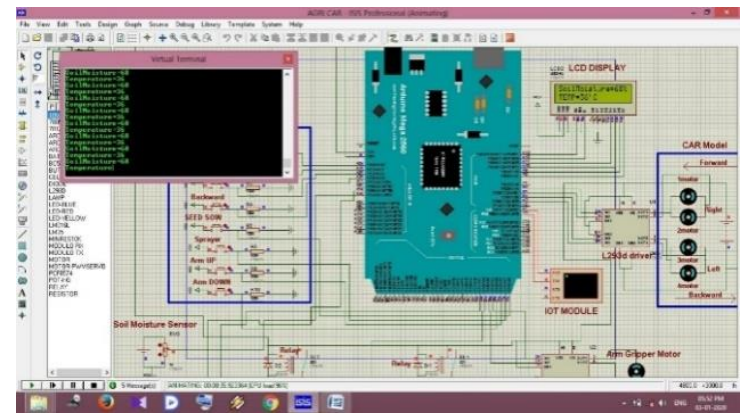

Fig .4. Simulation environment after obtaining output.

\section{IV.COMPONENTS USED IN AGRIBOT}

\section{A. POWER SUPPLY}

The motors, L293D driver, relays are powered with 12v.The Arduino Mega 2560,soil moisture sensor, temperature sensor, LCD display, IOT module are powered with 5v.

\section{B. L293D DRIVER}

L293D is the motor driver for managing servo motor to move in left, right, forward, backward direction. Servo motor is used for proper wheel movement.

\section{SERVO MOTOR}

Usually, the servo motor is a mixture of four components, namely a DC motor, a control circuit, a gear system and typically a position sensor as well as a potentiometer.

\section{RELAY}

The electrochemical relay uses a appropriate sensor such as limit switch to determine the gate closure and in effect help to stop a robot from working.

\section{E. LCD DISPLAY}

LCD display is a flat-panel monitor or other electronically modulated optical device using the light modulating properties of liquid crystals coupled with polarizers.

\section{F. SOIL MOISTURE SENSOR}

The soil humidity sensor is used to determine the volumetric soil water content. Used to measure moisture loss over time due to evaporation and uptake of plants.

\section{G. SPRAYER MOTOR}

Sprayer motor is powered with $12 \mathrm{v}$. High pressure diaphragm water pump with threaded interface and pressure transfer. This sprayer motor can be used in gardens, agriculture lands.

\section{H. WIFI CAMERA}

Strategically placed in farms to monitor the workers, growth of the crops, environment condition and so we can find the right time to harvest.

\section{ESP8266 MODULE}

This module allows microcontroller to connect to a Wi-Fi network and to use Hayes style commands to make simple TCP/IP connections.

\section{J. ARDUINO MEGA 2560}

Arduino Mega 2560 is an Atmega2560 based microcontroller board. Compared to other boards available on the market, it comes with more memory space and I/O pins. It comes with a USB cable port for attaching and copying code from machine to board. The DC power jack is when coupled to the board used for controlling the machine. This functionality is missing in some variant of Arduino board (for example., Arduino Pro mini does not come with DC power input).

\section{RESULT AND DISCUSSION}

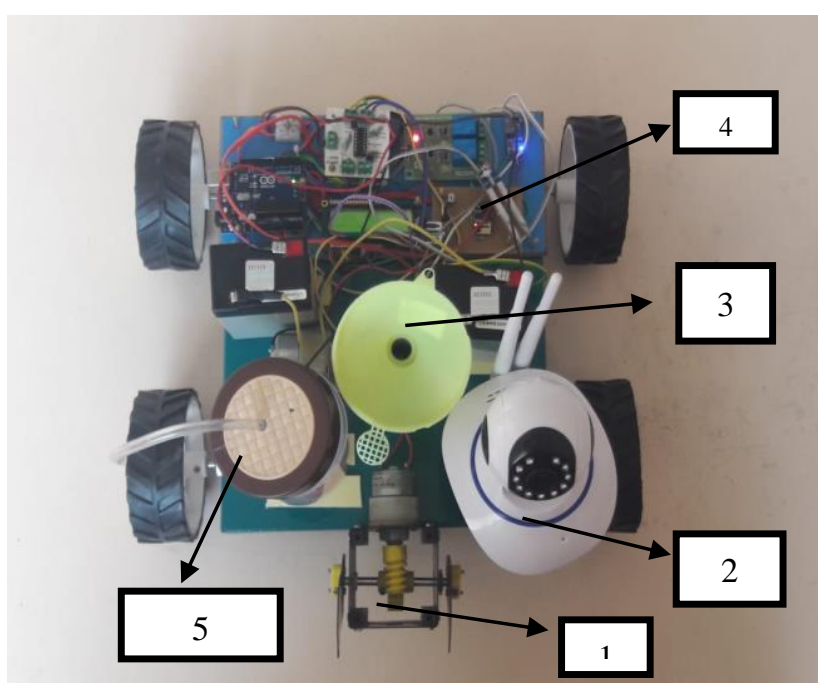

Fig .5.The proposed model hardware setup

The above Fig .5. is the proposed model of our project agribot. The "number 1" in the above figure is the arm gripper which is used to remove the unwanted crops from the farmland. The "number 2" in the above figure is the Wifi camera which is used to monitor the farmland from anywhere in the world. The "number 3" in the above figure is the seed dispenser which is used for seed sowing. The "number 4" in the above figure is used to detect the soil moisture content in the soil. The :number 5" in the above figure is the water pump which is used to spray the water. The above mentioned functions are carried out by the user using the designed android app (Fig .2.). 


\section{CONCLUSION AND FUTURE SCOPE}

In traditional method, the agriculturalist faced issues like lack of mechanization. Those days, the agricultural operations such as ploughing, weeding, spraying the fertilizer or water are carried out by humans using conventional tools. The proposed system is designed to ease the work of farmers and reduce the time consumption. Using IOT technology in our project, seed sowing, spraying of fertilizer and water, weeding processes are carried out.

In addition, we can add some features in this project like harvesting the crop at correct time and using image processing technique to detect and remove the infected leaves in the farmland.

\section{REFERENCES}

1. Mr.V.Gowrishankar, Dr.K.Venkatachalam,'IoT Based Precision Agriculture using Agribot",GRD Journals, Volume 03,Issue 05,April 2018.

2. Kavita Sapre,Shivani Savekar,Riya Sharma,Mayuri Chougule,'IOT Based Agri-bot for Backyard Farming",IRJET,Volume 05, Issue 04,April 2018.

3. Rahul D S,Sudarshan S K,Meghana K,Nandan K N,R Kirthana and Pallaviram Sure,'IOT Based Solar Powered Agribot For Irrigation and Farm Monitoring",ICISC 2018.

4. Shreyash Kulkarni,Rahul Kumbhar,Krunal Mistry,Shravan Nithurkar,'Multipurpose Agribot",IOSRJEN, Volume 09,Issue 04, April 2019.

5. https://www.delmhorst.com/blog/whats-the-ideal-moisture-level-forsoil-to-grow-crops.

\section{AUTHORS PROFILE}

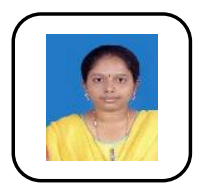

Shalini S, ME, Assistant Professor (ECE) in Sri Krishna College of Technology, Coimbatore. She has an industrial experience of 3 years and academic experience of 2.5 years. Her area of interest is Embedded and VLSI systems. She is a certified embedded software developer from ESSCI. She has published her papers in four international journals and one international conference. Email ID: shalusudhar89@gmail.com

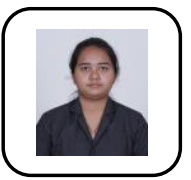

Kalaiselvi S, UG Scholar, Department of Electronics and Communication Engineering, Sri Krishna College of Technology,Coimbatore.

Email ID: 16tuec108@skct.edu.in

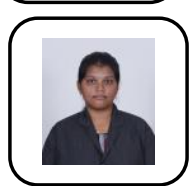

Logeshwari M, UG Scholar, Department of Electronics and Communication Engineering, Sri Krishna College of Technology, Coimbatore.

Email ID: 16tuec118@skct.edu.in

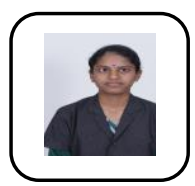

Pavithra P, UG Scholar, Department of Electronics and Communication Engineering, Sri Krishna College of Technology, Coimbatore.

ID:16tuec147@skct.edu.in 